\title{
Intertemporal self-selection with multiple buyers *
}

\author{
Mark Bagnoli ${ }^{1}$, Stephen W. Salant ${ }^{2}$, and Joseph E. Swierzbinski ${ }^{2}$ \\ ${ }^{1}$ Department of Finance, School of Business, Indiana University, Bloomington, IN 47405, USA \\ 2 Department of Economics, University of Michigan, Ann Arbor, MI 48109, USA
}

Received: October 4, 1993; revised version November 11, 1993

\begin{abstract}
Summary. We consider a monopolist selling durable goods to consumers with unit demands but different preferences for quality. The seller can offer items of different quality at the same time to induce buyers to self-select, as in Mussa-Rosen (1978), but is not artificially constrained to offer only one such menu. Instead the seller can offer without precommitment a sequence of menus over time. In the two-buyer case where the seller has complete information about each buyer's marginal valuation for quality, the seller's profits exceed what can be obtained from a single menu and sometimes approximate the profits of a perfectly discriminating monopolist. In companion papers (Bagnoli et al., 1990, 1992), we show that these conclusions continue to hold (1) in the infinite-horizon case with any finite number of buyers and (2) in two-period examples where the seller has incomplete information about buyer preferences.
\end{abstract}

\section{Introduction}

Consider the sole seller of a durable good. Suppose that buyers want at most one item but differ in their willingness to pay for quality. Assume the seller has complete information about each buyer's preferences. Since buyers differ, the seller has an incentive to price discriminate; but assume that he cannot offer an item to one buyer without making it available to everyone else. To price discriminate, the seller must induce buyers of one type to purchase a particular item while buyers of a different type purchase a different item.

In principle, the seller can induce self-selection in two ways. At any given time, he can offer items of different quality which will have differing appeal to the heterogeneous buyers. Alternatively, the seller may be able to induce intertemporal self-selection since anticipation of his future offers may lead some types of buyers to purchase a current item while others prefer to wait for something more appealing.

Each of these forms of self-selection has been studied extensively in the literature but mainly in isolation. For example, Coase's conjecture about the unprofitability of durable-goods monopoly spawned a literature on intertemporal self-selection; but since the monopolist in this literature can offer items of only a single quality, he 
cannot induce self-selection at a point in time. ${ }^{1}$ Mussa and Rosen (1978), on the other hand, examine self-selection at a point in time; but by constraining their monopolist to offer only a single menu of items, they eliminate the possibility of intertemporal self-selection.

We consider here the problem of a durable-goods monopolist who can make a sequence of offers to two heterogeneous buyers with unit demands but who cannot precommit. Since each buyer purchases at most one unit, the monopolist sells at most two units regardless of the number of offers he makes.

Suppose initially that the seller can make only a finite number of offers. If both buyers remain in the final period of this finite-horizon game, the equilibrium is identical to what Mussa-Rosen describe: in the absence of a corner solution, the monopolist finds it optimal to offer a menu of items to induce self-selection. The optimal menu necessarily contains items of inefficient quality and fails to extract the entire surplus.

In every period prior to the last, however, the monopolist finds it optimal to abandon menus. Instead, he offers a single item of efficient quality based on his observation of the marginal valuations of the remaining buyers.

Inducing self-selection over time turns out in this model to dominate inducing self-selection at a point in time. The monopolist offers a single item of a particular quality for sale and replaces it with an item of a different quality if and only if a sale occurs. Although the next item offered is more attractive to the previous purchaser than the item he actually purchased, that buyer is nonetheless rational to purchase the previous item. For he anticipates that the seller would not have made the subsequent item available until the previous item was purchased. By utilizing intertemporal self-selection - instead of point-in-time self-selection - the monopolist avoids having to distort the quality of the second item in order to make it unattractive to the first buyer; instead, he makes the second item unavailable (to either buyer) until the prior item is purchased.

The benefit of using intertemporal self-selection is that the monpolist can dispense with sales of inefficient quality. The cost is that he must space out his sales rather than make them at the same time. However, this cost becomes arbitrarily small for sufficiently high discount factors (i.e. a sufficiently short interval between offers). For such discount factors, the monopolist can increase the present value of his profits relative to Mussa-Rosen's single-offer case and sometimes receives approximately the present value obtained by a perfectly discriminating monopolist. Indeed, in the continuous-time limit, the monopolist can always approximate the present value of perfect price discrimination if the time horizon is sufficiently long.

In an infinite-horizon, complete-information game with an arbitrary but finite number of initial buyers, there exists a subgame-perfect equilibrium with the same characteristics as in the two-buyer case: no multi-item offers, no quality distortions, and, for discount factors sufficiently close to one, a present value for the monopolist that approximates the profits from perfect price discrimination. ${ }^{2}$

\footnotetext{
1 Contributions to this literature include Bagnoli, Salant, and Swierzbinski (1989), Bulow (1982), Coase (1972), Fudenberg, Levine, and Tirole (1985), Gul, Sonnenschein and Wilson (1986), Kahin (1986), Sobel and Takahashi (1983) and Stokey (1981).

2 For verification of these claims, see the appendix of Bagnoli et al. (1990).
} 
These results differ so markedly from the received wisdom on principal-agent problems (whether interpreted as applying to second-degree price discrimination, optimal regulation, or optimal income taxation) that readers may wonder whether they are mere artifacts of the assumption of complete information. However, a companion paper (Bagnoli et al. 1992) shows in a two-period, two-buyer game where the seller is uncertain about the realized distribution of buyer types that making a succession of offers rather than a single offer can still be advantageous provided buyer types are correlated (either positively or negatively). Indeed, the seller can sometimes extract under incomplete information virtually as much expected profit as a perfectly discriminating monopolist.

In section 2, we introduce our model and then review Mussa-Rosen's singleoffer case, which is also the two-buyer subgame in the final period of our finite-horizon model. In section 3, we examine the cases where the seller can make either a finite or an infinite number of sequential offers. Section 4 discusses the incomplete information analog of our results and concludes the paper.

\section{The model}

In this section, we first describe the model to be analyzed in the rest of the paper. Section 2.1 then briefly reviews the monopolist's optimal strategy in a single-period game.

We model the problem as a multi-period game, with the periods indexed by $t=1,2 \ldots T$. There are two stages in each period. In the first stage, the monopolist makes an offer consisting of a menu of items, with each item fully characterized by its quality level and price. In the second stage, each buyer simultaneously chooses whether to select a single item from among those offered or to continue to the next period. Buyers are assumed to have unit demands and select at most one item during the course of the game. Since the monopolist makes an offer in each period, the horizon, $T$, corresponds to the maximum number of distinct offers that the monopolist can make during the game. When $T$ is infinite, the number of offers that the monopolist can make is unbounded.

Initially, there are two buyers, labeled 1 and 2 . If buyer $i$ purchases an item of quality $q_{i}$ in period $t_{i}$ and pays price $p_{i}$, then he obtains the utility (discounted to $t=1)$ :

$$
U_{i}=\beta^{t_{i}-1}\left(v_{i} q_{i}-p_{i}\right),
$$

where $\beta$ is a discount factor assumed to be the same for all players, and $v_{i}$, buyer $i$ 's marginal valuation for quality, is a positive constant. We assume that $1>\beta>0$ and $v_{1}>v_{2}$. A buyer who chooses not to purchase in any period receives a utility of zero.

If buyer 1 accepts $\left(p_{1}, q_{1}\right)$ in period $t_{1}$ and buyer 2 accepts $\left(p_{2}, q_{2}\right)$ in $t_{2}$, then the present value received by the monopolist is:

$$
V=\beta^{t_{1}-1}\left(p_{1}-c\left(q_{1}\right)\right)+\beta^{t_{2}-1}\left(p_{2}-c\left(q_{2}\right)\right) .
$$

If only the single buyer $i$ purchases during the game (in period $t_{i}$ ), then the monopolist receives $\beta^{t_{i}-1}\left(p_{i}-c\left(q_{i}\right)\right)$, and if neither buyer makes a purchase, then 
the monopolist receives zero. Assume that $c^{\prime}(q), c^{\prime \prime}(q)>0$ for all $q$, that $c(0)=0$, and that $v_{2}>c^{\prime}(0) .^{3}$

All the parameters of the game, including the marginal valuation for quality of each buyer, are assumed to be common knowledge. We also assume that, although the monopolist has complete information and knows the marginal valuation of each specific buyer, he is legally barred from using this information to offer an item to one buyer which is unavailable to the other.

A player's strategy in each period specifies his action in that period as a function of time and anything else that he can observe - for example, the sequence of previous offers, the number of buyers purchasing specific price-quality pairs, the periods in which various items were purchased, the marginal valuations of the buyers who remain, and, for the buyers, the menu of prices and qualities offered in the first stage of the current period. The monopolist's strategy in each period specifies his offer in the first stage of the period as a function of these things. Similarly, a buyer's strategy specifies which price-quality pair (if any) to accept in the second stage of each period. The monopolist chooses his strategy to maximize the present value of his profits. Each buyer chooses a strategy to maximize his own utility.

\subsection{The optimal offer in a single-period game}

Mussa and Rosen (1978) assumed that the monopolist's first offer was also his last offer $(T=1)$. For purposes of comparison, we begin by briefly summarizing their findings.

In the subgame-perfect equilibrium of this one-offer game, the monopolist adopts the following strategy. The monopolist offers $\left(p_{1}, q_{1}\right)$ and $\left(p_{2}, q_{2}\right)$ in order to:

$$
\max \left(p_{1}-c\left(q_{1}\right)\right)+\left(p_{2}-c\left(q_{2}\right)\right)
$$

subject to the constraints:

$$
\begin{aligned}
p_{i}, q_{i} & \geq 0 \quad \text { for } i=1,2 \\
v_{1} q_{1}-p_{1} & \geq 0 \\
v_{2} q_{2}-p_{2} & \geq 0 \\
v_{1} q_{1}-p_{1} & \geq v_{1} q_{2}-p_{2} \\
v_{2} q_{2}-p_{2} & \geq v_{2} q_{1}-p_{1} .
\end{aligned}
$$

The optimal strategy for each buyer in the second stage is to choose the best item offered in the first stage that generates nonnegative utility. Equations ( $3 b$ ) and (3c) are "participation" constraints indicating that buyers will only purchase items which generate nonnegative utility. Equations (3d) and (3e) are "self-selection" constraints. Equation (3d) states that $\left(p_{1}, q_{1}\right)$, the item intended for buyer 1 , will only be purchased by buyer 1 if it generates utility for him that is at least as high

\footnotetext{
3 The assumption that $v_{2}>c^{\prime}(0)$ is sufficient to ensure that both buyers are served under perfect price discrimination and that at least buyer 1 is served in Mussa-Rosen's problem.
} 
as the utility generated by the alternative item. Equation (3e) has a similar interpretation for buyer 2 .

The optimization problem specified by equations (3a) through (3e) has been extensively analyzed in the literature: it has a unique solution. Moreover, at the optimum, $q_{1} \geq q_{2}$ and, for any pair of qualities that satisfy this inequality, the profit-maximizing prices $p_{1}$ and $p_{2}$ are determined by the self-selection constraint for buyer 1 and the participation constraint for buyer 2, both of which are binding.

By solving the binding constraints (equations (3c) and (3d)) for $p_{1}$ and $p_{2}$ and substituting the resulting expressions in equation (3a), we obtain a strictly concave objective function in $q_{1}$ and $q_{2}$ which is maximized subject only to the constraint that $q_{1} \geq q_{2} \geq 0$. Solving the resulting optimization problem, we obtain for $q_{1}$ : $v_{1}-c^{\prime}\left(q_{1}\right)=0$. As for $q_{2}$, there are two possibilities: Either $q_{2}>0$ and $2 v_{2}-v_{1}-$ $c^{\prime}\left(q_{2}\right)=0$ or, alternatively, $q_{2}=0$ and $2 v_{2}-v_{1}-c^{\prime}(0) \leq 0$. In this "corner case," the interpretation of $q_{2}=0$ is that buyer 2 is not served. In either the interior or the corner case, the binding constraints ( $3 \mathrm{c}$ ) and (3d) can be solved to yield the optimal prices $\left(p_{i}\right)$.

If $2 v_{2}-v_{1}-c^{\prime}(0)>0$, then it is optimal for the monopolist to sell to both buyers. Let $\left(p_{i}^{M R}, q_{i}^{M R}\right)$ denote the item purchased by buyer $i$ in this case. It will be convenient to define the following additional variables for the interior case: $\pi_{i}^{M R}, V^{M R}$, and $U_{i}^{M R}$. Let $\pi_{i}^{M R}$ denote the profit the monopolist derives from buyer $i$ when he sells to both buyers:

$$
\pi_{i}^{M R}=p_{i}^{M R}-c\left(q_{i}^{M R}\right) .
$$

Let $V^{M R}$ denote the sum of the payoffs which the monopolist collects from the buyers in this case:

$$
V^{M R}=\pi_{1}^{M R}+\pi_{2}^{M R} .
$$

Let $U_{i}^{M R}$ denote the equilibrium payoff of buyer $i$ in this case. That is, $U_{2}^{M R}=v_{2} q_{2}^{M R}-p_{2}^{M R}=0$ and $U_{1}^{M R}=v_{1} q_{1}^{M R}-p_{1}^{M R}$.

In contrast, recall that a perfectly discriminating monopolist with complete information is less heavily constrained. He can offer an item to one buyer while making it unavailable to the other buyer. Therefore his objective function is the same as (3a) but he is restricted only by the two participation constraints ( $3 b$ and $3 c)$ - and not by either self-selection constraint. The profit obtained from each type $i$ buyer will be $v_{i} q_{i}-c\left(q_{i}\right)$. The optimal item for such a monopolist to offer to a type $i$ buyer has a price and quality level denoted by $\left(p_{i}^{1 s t}, q_{i}^{1 s t}\right)$ and specified by the equations:

$$
\begin{aligned}
p_{i}^{1 s t} & =v_{i} q_{i}^{1 s t}, \\
c^{\prime}\left(q_{i}^{1 s t}\right) & =v_{i} .
\end{aligned}
$$

Since the monopolist can extract all of the surplus from each buyer, he offers each the "efficient" quality level (which maximizes total surplus).

Let $\pi_{i}^{1 s t}$ denote the profit that the monopolist obtains when buyer $i$ accepts the optimal take-it-or-leave-it offer specified in equations (6a) and (6b).

$$
\pi_{i}^{1 s t}=p_{i}^{1 s t}-c\left(q_{i}^{1 s t}\right)
$$


The buyer with the higher marginal valuation for quality (buyer 1) always receives the same quality level from the Mussa-Rosen monopolist as he would from a perfectly discriminating monopolist. Since the offer of the perfectly discriminating monopolist would violate the self-selection constraint of buyer 1, the Mussa-Rosen monopolist can never extract the entire surplus.

\section{Optimal sequential offers}

In this section, we consider the gains which the monopolist can achieve by making a sequence of offers to the two buyers instead of a single offer. Making a sequence of offers is advantageous because it induces different buyers to purchase in different periods. For discount factors sufficiently close to one, we will show that the monopolist can always increase the present value of his profits by making a succession of single-item offers.

Suppose now that $T>1$. We consider in turn the two parameter regimes which gave rise in Mussa-Rosen's single-offer case, respectively, to corner and interior equilibria. Section 3.1 studies the corner case. Sections 3.2 and 3.3 consider the interior parameter regime and games with finite (3.2) and infinite (3.3) horizons. Finally, Section 3.4 considers a continuous-time limit of our model.

In each case, we begin by describing the subgame-perfect equilibrium strategies for each of the three players. Having described them, we then verify that each strategy is optimal in every subgame given the other strategies.

\subsection{Subgame-perfect equilibrium with a finite or infinite horizon: The corner parameter regime}

In the "corner" regime where $2 v_{2}-v_{1}-c^{\prime}(0) \leq 0$, the following strategy combination forms a subgame-perfect equilibrium in both in finite- and the infinite-horizon games. In each period, each buyer accepts the best offer (if any) of those which generate nonnegative utility for him. We refer to this strategy as the "get-it-whileyou-can" strategy since the buyer seizes the first opportunity for surplus as if no future opportunities might present themselves.

The monopolist uses the following strategy in period $t$. If buyer 1 or both buyers remain in the game at the beginning of the period, then the monopolist offers the single price-quality pair $\left(p_{1}^{1 s t}, q_{1}^{1 s t}\right)$ defined by equations (6a) and (6b). If only buyer 2 remains, then the monopolist offers the single price-quality pair $\left(p_{2}^{1 s t}, q_{2}^{1 s t}\right)$.

Next, we verify that these strategies are subgame perfect. In both finite- and infinite-horizon games, no buyer can ever obtain positive utility when the monopolist uses the proposed strategy. Hence, it is optimal for each buyer to use the get-itwhile-you-can strategy in each period.

Finally, we verify the optimality of the seller's strategy when buyers use the get-it-while-you-can strategy in each period. In any period with only one remaining buyer, the proposed strategy is clearly optimal for the monopolist since it extracts the maximum possible surplus from this buyer.

Suppose instead that both buyers remain. Any price-quality pair (with $q>0$ ) that generates nonnegative utility for buyer 2 generates strictly positive utility for 
buyer 1. Hence, it is infeasible - given the buyers' strategies - for the monopolist to sell only to buyer 2 . This leaves the monopolist two choices: sell immediately to both buyers or sell only to buyer 1 . Among all the offers which only buyer 1 would accept, the proposed offer is clearly optimal for the monopolist since it extracts the maximum possible surplus from buyer 1 . Moreover, since for this parameter regime a corner solution is optimal in the single-period game, the profit from selling only to buyer 1 must strictly exceed the profit from selling simultaneously to the two buyers.

Indeed, if at least one future period remains, the proposed strategy is even more profitable than in the single-offer case since the opportunity to make future offers enables the seller to extract the entire surplus of buyer 2 in the next period. Hence, the proposed sequential strategy results in the following present value for the monopolist:

$$
V^{S}=\pi_{1}^{1 s t}+\beta \pi_{2}^{1 s t} .
$$

The above arguments demonstrate that when $2 v_{2}-v_{1}-c^{\prime}(0) \leq 0$, the proposed strategy combination constitutes a subgame-perfect equilibrium for the completeinformation game with any horizon length, either finite or infinite. Moreover, these strategies constitute a subgame-perfect equilibrium for any discount factor between zero and one. In any game in which the monopolist can make two or more offers $(T \geq 2)$, the monopolist receives the equilibrium present value specified in equation (8). This present value strictly dominates the profit obtained by a static Mussa-Rosen strategy and approaches $\pi_{1}^{1 s t}+\pi_{2}^{1 s t}$, the profit obtained by a perfectly discriminating monopolist, as the discount factor approaches one.

\subsection{Subgame-perfect equilibrium with a finite horizon: The interior parameter regime}

We now consider the "interior" regime where $2 v_{2}-v_{1}-c^{\prime}(0)>0$. Since we are ultimately interested in the play of the game when the time interval between successive offers becomes negligible, we focus on the equilibrium strategies when the discount factor pertaining to the interval between offers approaches one.

\subsubsection{The players' strategies}

For discount factors sufficiently close to one, the subgame-perfect equilibrium strategies in the finite-horizon game may be described as follows. Buyer 2 uses the get-it-while-you-can strategy in each period. Buyer 1 uses the get-it-while-you-can strategy in any subgame where he is the sole remaining buyer. In addition, buyer 1 always uses the get-it-while-you-can strategy in the final period of the game $(t=T)$ whether or not buyer 2 remains. Finally, if both buyers remain prior to $T$, buyer 1 uses the get-it-while-you-can strategy in the current period whenever he anticipates being the only remaining buyer from the next period onward; buyer 1 will anticipate being isolated if he observes that some item currently offered by the monopolist will provide nonnegative utility for buyer 2 .

If both buyers remain prior to $T$ and if buyer 1 observes that no item offered will yield nonnegative utility to buyer 2 , then buyer 1 is more selective: in the current 
period $t$ he will accept the best price-quality pair (if any) of those that generate utility (discounted to period 1) greater than or equal to the reservation utility (also discounted to period 1) $\beta^{T-1} U_{1}^{M R}$. Buyer l's strategy is a generalization of the get-it-while-you-can strategy to the case where the discounted reservation utility is $\beta^{T-1} U_{1}^{M R}$.

As for the description of the seller's strategy, he will offer a single item of efficient quality priced so as to extract the entire surplus in any period where only one buyer remains. If both buyers remain in the final period, the monopolist will offer the Mussa-Rosen menu. If both buyers remain prior to $T$, the monopolist will offer the single quality $q_{1}^{1 \text { st }}$ at a price $p(t)$ which is given by the equation:

$$
p(t)=\left(1-\beta^{T-t}\right) p_{1}^{1 s t}+\beta^{T-t} p_{1}^{M R} .
$$

In equilibrium, buyer 1 accepts $\left(p(1), q_{1}^{\text {ist }}\right)$ in the first period and buyer 2 accepts $\left(p_{2}^{1 s t}, q_{2}^{1 s t}\right)$ in the second period.

\subsubsection{Optimality of the buyers' strategies}

To verify that the buyers' strategies are subgame perfect, note first that the get-it-while-you-can strategy is optimal for buyer 2 since he can never obtain positive utility when the monopolist uses his equilibrium strategy. For the same reason, the get-it-while-you-can strategy is optimal for buyer 1 when he is the sole remaining buyer. Since a failure to accept an offer in the final period results in zero utility, the get-it-while-you-can strategy is also optimal for buyer 1 in the final period whether or not buyer 2 remains. Finally, if the monopolist offers a price-quality pair that provides nonnegative utility for buyer 2 , then buyer 2 , using the get-it-whileyou-can strategy, will accept it; buyer 1 can therefore expect only zero utility in future periods, and the get-it-while-you-can strategy is also optimal for him in this case.

If both buyers remain prior to $T$ and the monopolist offers no item in period $t$ which gives buyer 2 nonnegative utility, then buyer 1 anticipates that buyer 2 will remain and that the seller will offer $q_{1}^{1 s t}$ in the next period at a price of $p(t+1)$ defined in equation (9). For all $t+1<T$, equation (9) implies that $p(t+1)>p_{1}^{M R}$. Hence, the previous analysis of the single-offer game indicates that buyer 2 will reject such an offer. More generally, buyer 1 can anticipate that as long as he declines to purchase, the monopolist will continue to offer $\left(p(s), q_{1}^{1 s t}\right)$ in any period $t<s<T$ and that buyer 2 will continue to reject these offers. Moreover, by substituting equations (6a) and (9) into equation (1) and using the fact that $U_{1}^{M R}=p_{1}^{1 s t}-p_{1}^{M R}$, it is straightforward to verify that buyer 1 obtains the same discounted utility, $\beta^{T-1} U_{1}^{M R}$, by accepting any of the offers $\left(p(s), q_{1}^{1 s t}\right)$.

Finally, suppose that buyer 1 declines to purchase until the final period. In this case, he can anticipate that as his final act the monopolist would offer the Mussa-Rosen menu and that buyer 1 would again earn the discounted utility $\beta^{T-1} U_{1}^{M R}$ by accepting an item from this menu. Hence, in any future period including the last, the buyer expects to obtain the discounted utility $\beta^{T-1} U_{1}^{M R}$ if he fails to accept the monopolist's offer in period $t$ when both buyers remain. It is thus optimal for buyer 1 to accept the best offer in period $t$ of those that provide 
discounted utility greater than or equal to $\beta^{T-1} U_{1}^{M R}$; that is, it is optimal for buyer 1 to use generalized get-it-while-you-can-strategy with discounted reservation utility $\beta^{T-1} U_{1}^{M R}$.

\subsubsection{Optimality of the seller's strategy}

To complete the verification of subgame perfection, we consider the optimality of the seller's strategy. As in the corner parameter regime, the proposed strategy is clearly optimal for the monopolist in any subgame with one remaining buyer since it extracts the maximum possible surplus from such a buyer. Moreover, as previously noted, the Mussa-Rosen menu is optimal for the monopolist in the final period when both buyers remain.

If two buyers remain prior to the final period, the monopolist has two choices just as in the previous parameter regime: sell immediately to both buyers or sell only to buyer 1 . We now verify that, for sufficiently high discount factors, the seller will never make an offer containing two items prior to the final period. To sell simultaneously to both buyers, the monopolist must provide buyer 2 with nonnegative utility. But this will make buyer 1 anticipate isolation and he too will accept the best offer generating nonnegative utility. The analysis of the single-offer game demonstrates that when both buyers require nonnegative utility to participate and $2 v_{2}-v_{1}-c^{\prime}(0)>0$, the static Mussa-Rosen offer is the most profitable twoitem offer for the seller and results in a payoff of $\pi_{1}^{M R}+\pi_{2}^{M R}$.

The monopolist can easily dominate this best two-item offer provided he can make at least one future offer (that is, if $t<T$ ). For, suppose the monopolist simply deleted the lower quality item from the Mussa-Rosen offer. Buyer 2 will not accept the remaining item since it provides him with negative utility (as it did when it was part of the Mussa-Rosen menu). On the other hand, buyer 1 can obtain the discounted utility of $\beta^{t-1} U_{1}^{M R}$ by accepting the remaining item in period $t$. Since $\beta^{t-1} U_{1}^{M R}>\beta^{T-1} U_{1}^{M R}$, buyer 1 - using his equilibrium strategy - would purchase the item. Hence, the monopolist can anticipate that buyer 1 will accept the offer and buyer 2 will reject it. The seller could then offer $\left(p_{2}^{1 s t}, q_{2}^{1 s t}\right)$ next period and, since it would provide buyer 2 with nonnegative utility, could anticipate that the offer would be accepted. This strategy yields the seller $\pi_{1}^{M R}+\beta \pi_{2}^{1 \text { st }}$. For $\beta>\beta^{*}$ where $\beta^{*}=$ $\pi_{2}^{M R} / \pi_{2}^{1 s t}$ this payoff strictly exceeds the payoff from the two-item Mussa-Rosen offer.

Of course, this strategy - while superior to any two-item menu - is not the best single-item offer. Recall that in any period $t$ prior to the last period $(t<T)$, if both buyers remain and buyer 1 does not anticipate that buyer 2 will make a purchase in period $t$, then buyer 1 will accept the best offer yielding discounted utility $\beta^{T-1} U_{1}^{M R}$. The monopolist should therefore continue to offer $q_{1}^{1 s t}$ since that maximizes the total surplus; but he should price it so as to extract all but the minimum surplus necessary for buyer 1 to purchase. The price of the proposed dominating offer $\left(p_{1}^{M R}\right)$ is suboptimal since it gives $U_{1}^{M R}$ to buyer 1 when he requires, in terms of period $t$ utility, only $\beta^{T-t} U_{1}^{M R}$. The optimal price should therefore be $p(t)=p_{1}^{M R}+\left(U_{1}^{M R}-\beta^{T-t} U_{1}^{M R}\right)$. Using the fact that $U_{1}^{M R}=p_{1}^{1 s t}-p_{1}^{M R}$, we conclude that the optimal price for the item of quality $q_{1}^{1 s t}$ is given by equation (9). 
The above discussion demonstrates that the proposed strategies constitute a subgame-perfect equilibrium in the two-buyer, finite-horizon game with complete information for any $\beta>\beta^{*}$. In equilibrium, the monopolist sells a unit of quality $q_{1}^{1 s t}$ to buyer 1 in the first period at a price given by $p(1)$ in equation (9) and makes the offer $\left(p_{2}^{1 s t}, q_{2}^{1 s t}\right)$ to buyer 2 in the second period. Substituting these prices and qualities into equation (2) and collecting terms using equations (4) and (7), we obtain the following expression for the equilibrium present value obtained by the monopolist in the play of the $T$-period game:

$$
V_{T}=\left(1-\beta^{T-1}\right) \pi_{1}^{1 s t}+\beta^{T-1} \pi_{1}^{M R}+\beta \pi_{2}^{1 s t} .
$$

\subsection{Subgame-perfect equilibrium with an infinite horizon: The interior parameter regime}

For infinite-horizon games with complete information and sufficiently high $\beta$, the analysis when $2 v_{2}-v_{1}-c^{\prime}(0)>0$ is virtually identical to the analysis for the corner parameter regime. In the infinite-horizon game, the use in each period of the get-it-while-you-can strategy by each buyer and the strategy where the monopolist offers a single-item menu which extracts the entire surplus of the remaining buyer with the highest marginal valuation constitutes a subgame-perfect equilibrium. The equilibrium present value obtained by the monopolist, $V^{S}$, is given by equation (8).

As in the corner parameter regime, the get-it-while-you-can strategy is optimal for each buyer since the buyers can anticipate only zero utility in future periods. The strategy proposed for the seller is optimal if $V^{S}>V^{M R}$. A comparison of equations (5) and (8) indicates that $V^{S}>V^{M R}$ if $\beta>\beta^{*}$. In the play of the equilibrium, the monopolist makes the offer $\left(p_{1}^{1 s t}, q_{1}^{1 s t}\right)$ in the first period.

It can be verified by working backwards that whenever the horizon is finite the subgame-perfect equilibrium is essentially unique. ${ }^{4}$ In contrast, there are a continuum of equilibria in the infinite-horizon case. The particular infinite-horizon equilibrium that we discuss was chosen because the strategies supporting it are the limiting strategies in the finite-horizon case for a sufficiently long horizon. Buyer 2 in either case accepts the best offer in a period yielding nonnegative utility. Buyer 1 in the infinite-horizon case also accepts such offers and in the finite-horizon case adopts the identical strategy prior to $T$ except when two buyers remain and no current item would give buyer 2 nonnegative utility. In such circumstances, buyer 1 purchases the best item offered provided it yields $\beta^{T-1} U_{1}^{M R}$. But this strategy becomes virtually the same as "get-it-while-you-can" as $T$ becomes large. Recall that when the monopolist is restricted to a maximum of $T$ offers, he makes the offer $\left(p(1), q_{1}^{1 s t}\right)$ in the first period, with $p(1)$ given in equation (9), and obtains the equilibrium present value, $V_{T}$, given in equation (10). For each fixed value of $\beta$ greater than $\beta^{*}$, equations (8), (9), and (10) indicate that the monopolist's first-period

\footnotetext{
${ }^{4}$ A trivial multiplicity of equilibria arises because the seller can always add items to the menu which are unacceptable to every remaining buyer. Even in the absence of such items, a second trivial multiplicity of equilibria arises because of buyer 2's indifference about accepting offers off the equilibrium path yielding zero utility. However, the play of the game and the payoffs which result in these equilibria are unique.
} 
offer and present value in the $T$-period game approach the infinite-horizon first-period offer, $\left(p_{1}^{1 s t}, q_{1}^{1 s t}\right)$, and the present value obtained in the infinite-horizon game as $T$ becomes large. $\left(p(1) \rightarrow p_{1}^{1 \text { st }}\right.$ and $V_{T} \rightarrow V^{S}$ as $T \rightarrow \infty$.)

\subsection{The continuous-time limit}

One way to relate the periods in our game to calendar time is to assume that a fixed, finite interval of calendar time, $\delta$, must elapse between successive offers. If it is also assumed that there is a maximum amount of time, $\Gamma$, after which the game must end, then $T$, the maximum number of offers which the monopolist can make, is related to the time horizon, $\Gamma$, via the equation:

$$
T=\frac{\Gamma}{\delta}
$$

If the game has an infinite time horizon, then there is no apriori bound on the maximum number of offers; that is, $T=\infty$.

If $\rho$ is a fixed parameter expressing the common instantaneous rate of time preference of the buyers and the monopolist, then $\beta$, the discount factor for the time interval between successive offers is related to $\rho$ and $\delta$ via the equation:

$$
\beta=\exp [-\rho \delta] \text {. }
$$

Using the above formulation, we can define a continuous-time limit to our game by allowing the interval between successive offers $\delta$ to approach zero. In this case, although the discount factor for any fixed time interval (e.g. one year) remains constant, $\beta$ must approach one.

In the infinite-horizon game, the monopolist obtains the present value $V^{S}$ in both parameter regimes. As the time between successive offers shrinks to zero, the monopolist receives a present value equal to that obtained by a perfectly discriminating monopolist, $\pi_{1}^{1 s t}+\pi_{2}^{1 s t}$.

In finite-horizon games (with $T \geq 2$ ), the monopolist also receives the present value $V^{S}$ when $2 v_{2}-v_{1}-c^{\prime}(0) \leq 0$. Hence, in the continuous-time limit, he also receives the present value obtained by a perfectly discriminating monopolist.

For the parameter regime $2 v_{2}-v_{1}-c^{\prime}(0)>0$, however, the monopolist cannot in the continuous-time limit achieve the present value attainable under perfect price discrimination when the horizon length is fixed. For, in that case, buyer 1 can always hold out for the monopolist's final offer and be assured a strictly positive surplus.

To analyze the behavior of the initial price and the monopolist's present value of profit in this parameter regime as a function of the fixed time horizon and the interval between offers, we proceed as follows. As the interval between successive offers $(\delta)$ shrinks, $\beta$ strictly increases while the threshold level $\beta^{*}$ remains constant. Thus, for any fixed time horizon $\Gamma$, deviating from the static Mussa-Rosen strategy becomes optimal for the monopolist if the time interval between offers is sufficiently short. The monopolist then receives the present value $V_{T}$ specified in equation (10). By using equations (11) and (12) to substitute for $T$ and $\beta$ in equations (9) and (10), we can rewrite the equations for $p(1)$, the price at which the monopolist sells to buyer 1 in the first period, and for $V_{T}$ in terms of the "time parameters" $\delta, \Gamma$, and 
$\rho$. Let $V_{\Gamma}$ denote the present value obtained by the monopolist when the time horizon is $\Gamma, 2 v_{2}-v_{1}-c^{\prime}(0)>0$, and $\beta>\beta^{*}$.

$$
\begin{gathered}
p(1)=\left(1-e^{-\rho[\Gamma-\delta]}\right) p_{1}^{1 s t}+e^{-\rho[\Gamma-\delta]} p_{1}^{M R} . \\
V_{\Gamma}=\left(1-e^{-\rho[\Gamma-\delta]}\right) \pi_{1}^{1 s t}+e^{-\rho[\Gamma-\delta]} \pi_{1}^{M R}+e^{-\rho \delta} \pi_{2}^{1 s t} .
\end{gathered}
$$

It is straightforward to set $\delta=0$ in equations (13) and (14) to determine the limiting expressions for $p(1)$ and $V_{\Gamma}$ as the interval between offers shrinks to zero. For a finite time horizon, $\Gamma, p(1)<p_{1}^{1 s t}$ and $V_{\Gamma}<V^{S}$, even when $\delta=0$.

However, for any fixed $\delta$ (and for the limiting case where $\delta=0$ ), $p(1) \rightarrow p_{1}^{1 s t}$ and $V_{\Gamma} \rightarrow V^{S}$ as $\Gamma \rightarrow \infty$. When the time horizon becomes large, the monopolist in the finite-horizon game uses almost the same strategy in the first period and obtains almost the same present value as in the infinite-horizon game. Moreover, as $\delta \rightarrow 0$ and $\Gamma \rightarrow \infty, p(1) \rightarrow p_{1}^{1 s t}$ and $V_{\Gamma} \rightarrow \pi_{1}^{1 s t}+\pi_{2}^{1 s t}$. As the interval between successive offers becomes small and the time horizon becomes large, the monopolist makes the same offers and receives the same present value as the perfectly discriminating monopolist.

\section{Conclusion}

In this paper, we have considered the case of a monopolist selling durable goods to two consumers with unit demands but different preferences for quality. Under the assumption that the seller has complete information about the preferences of each buyer, we showed that the seller can increase his profits by making a succession of offers rather than a single offer. Indeed, sometimes the seller can approximate the profits of a perfectly discriminating monopolist. In a companion paper (Bagnoli et al., 1990), we show in the infinite-horizon case that these conclusions continue to hold for any finite number of buyers.

These results are novel and some readers may be inclined to dismiss them as mere artifacts of complete information. As shown in Bagnoli et al. (1992), however, the seller can also benefit from making a succession of offers if he has incomplete information about the preferences of each buyer.

Recall the finite-horizon, corner case of the previous section. Suppose, for simplicity, that there are two periods and the discount factor is one. In the play of the subgame-perfect equilibrium, recall that the monopolist offers $\left(p_{1}^{1 s t}, q_{1}^{1 s t}\right)$ in the first period which the high-valuation buyer always accepts and $\left(p_{2}^{1 s t}, q_{2}^{1 s t}\right)$ in the second period which the low-valuation buyer always accepts. Since the discount factor is one, the monopolist achieves the profit of a perfectly discriminating monopolist.

Suppose instead the seller has incomplete information at the outset about the valuations of the two buyers. Suppose he assigns positive probability to the pair of buyers having different valuations and complementary positive probability to their having the lower valuation. As shown in Bagnoli et al. (1992), a perfect Bayesian equilibrium exists for the corner parameter regime in which the seller offers the single item $\left(q_{1}^{1 s t}\right)$ in the first period at a price which may leave some surplus to a high valuation buyer purchasing it but provides only negative surplus to any low valuation purchaser. If a purchase does occur in the first period, the seller concludes 
that the remaining buyer must have a low valuation and extracts the entire surplus from him using a single-item offer; if no purchase occurs in the first period, the seller revises his prior beliefs - taking into account that a high valuation buyer rejects the first offer with some probability - and devises a two-item menu which induces low valuation buyers to purchase and any high valuation buyer remaining to be indifferent between purchasing then and in the previous period. As the exogenous prior probability of the two buyers having different valuations approaches one, the equilibrium surplus left to a high valuation buyer if he purchases in the first period approaches zero (as does his surplus from the two-item menu which would follow if he does not purchase initially) and the probability that he accepts the initial offer approaches unity. Hence, in the play of the perfect Bayesian equilibrium, the high valuation buyer almost surely purchases quality $q_{1}^{1 s t}$ in the first period, the low valuation buyer almost surely purchases $q_{2}^{1 s t}$ in the second period, and the prices they pay result in the seller extracting virtually as much surplus as a perfectly discriminating monopolist. The introduction of incomplete information complicates the analysis but does not alter the conclusions.

In the current paper and its predecessors (Bagnoli et al., 1989, 1990, 1992), we maintain the following assumptions - whether or not the seller has complete information. The seller initially faces a finite number of buyers. After each period, the monopolist can observe accurately both the number of items purchased and also their descriptions. In the complete information case (and only in that case), the seller has additional information since he can also observe the preference of each remaining buyer. The seller can base future offers on all the information available to him. Under these maintained assumptions, the seller often benefits from making a succession of offers rather than a single offer and sometimes approximates the profits of perfect price discrimination.

Previous studies have reached opposite conclusions because they are based on different assumptions. In previous studies, the seller is instead assumed to face a continuum of buyers and to be either unable to observe the purchase of any single buyer or unable to condition future actions upon his observation. This seemingly innocuous difference in assumptions generates strikingly different conclusions. ${ }^{5}$

\section{References}

Bagnoli, M., Salant, S. W., Swierzbinski, J.: Durable-goods monopoly with discrete demand. J. Polit. Econ. 97, 1459-1478 (1989)

Bagnoli, M., Salant, S. W., Swierzbinski J.: Price discrimination and intertemporal self-selection. Center for Research on Economic and Social Theory (CREST) Working Paper 91-1, University of Michigan, 1990

Bagnoli, M., Salant, S. W., Swierzbinski, J.: Intertemporal self-selection with multiple buyers under complete and incomplete information. Center for Research on Economic and Social Theory (CREST) Working Paper 92-05, University of Michigan, 1992

Bulow, J.: Durable-goods monopolists. J. Polit. Econ. 90, 314-332 (1982)

Coase, R.: Durability and monopoly. J. Law Econ. 15, 143-149 (1972)

\footnotetext{
${ }^{5}$ Levine and Pesendorfer (1992) discuss this difference in assumptions and cite other literatures where a similar modeling issue arises.
} 
Fudenberg, D., Levine, D., Tirole, J.: Infinite-horizon models of bargaining with one-sided incomplete information. In: A. Roth (ed.) Game-theoretic models of bargaining, pp. 73-98. Cambridge: Cambridge University Press, 1985

Gul, F., Sonnenschein, H., Wilson, R.: Foundations of dynamic monopoly and the coase conjecture. J. Econ. Theory 39, 155-190 (1986)

Kahn, C.: The durable goods monopolist and consistency with increasing costs. Econometrica 54, 275-294 (1986)

Levine, D., Pesendorfer, W.: When are agents negligible. Unpublished manuscript 1992

Mussa, M., Rosen, S.: Monopoly and product quality. J. Econ. Theory 18, 301-317 (1978)

Sobel, J., Takahashi, I.: A multistage model of bargaining. Rev. Econ. Stud. 50, 411-426 (1983)

Stokey, N.: Rational expectations and durable goods pricing. Bell J. Econ. 12, 112-128 (1981) 